\title{
REDESIGNING PROBABILITY \& STATISTICS FOR ENGINEERS COURSE BY DEVELOPING A CUSTOM TEXTBOOK AND REFOCUSING LECTURES ON PROBLEM SOLVING
}

\author{
R. Arief Budiman \\ Department of Mechanical and Manufacturing Engineering, University of Calgary \\ Email: rbudiman@ucalgary.ca
}

\begin{abstract}
The two-year experience of teaching and redesigning a probability and statistics for engineers course at the Schulich School of Engineering will be discussed through the lens of (i) writing and using a custom textbook for the course and (ii) refocusing lectures on applying concepts to solving problems. The course redesign, for example, allows students to develop conceptual and practical understanding on selecting the most appropriate probability distribution for a given problem. The refocusing of lectures to problem solving proves very useful for students. Further textbook development is briefly discussed.
\end{abstract}

\section{INTRODUCTION}

Second-year Probability and Statistics for Engineers ENGG 319 course at the Schulich School of Engineering is a common core course and taught to engineering students at the School with the exception of students from Electrical Engineering and Computer Engineering, who take a similar course from their programs. ENGG 319 is offered in Fall term and has about 540 students split into 4 sections. Students in each section are from different programs except the two program mentioned.

I started teaching ENGG 319 in Fall 2012 and had a desire to teach it by explaining concepts in details and providing a sufficient number of class examples. I have never taught a probability and statistics for engineers before, but my research area is statistical mechanics and phase transitions, so that at the very least I understand the connections among probability distribution functions, combinatorics, and their applications. I have taught several courses previously, from dynamics to materials engineering, which allowed me to compare the Probability and Statistics for Engineers (PSE) with with other courses.

The PSE course is more straightforward than an engineering dynamics course that has to apply governing equations of motion with various geometrical constraints and initial conditions from different problems. The PSE course does not have to combine several ideas and physical considerations as required when selecting optimum materials or heat treatment using iron-carbon phase diagrams in a materials engineering course. The PSE course is essentially an applied mathematics course with clear connections sequentially from theorems of probability to combinatorics to probability distribution functions. When these connections become clear to students, it should be relatively easy for the students to apply the PSE concepts to solving problems.

The standard PSE textbooks [1-3] start with roles of statistics in engineering, data collecting, and data presentation. These introductory topics occupy $5 \%$ of the textbook. By the time random variables and probability theorems are discussed students have to read about 60 pages of text. The first glimpse of probability distribution functions doesn't arrive until around page 80 . Such standard textbook has many tables and figures and a typical student is estimated to spend 5 minutes/page of focused reading time. 
A student has to spend about 8 focused reading hours to be introduced to probability distribution functions. Including exercise problems, it is reasonable to expect 12 study hours to reach the probability distribution function chapter. It takes about 6 lecture hours in 2 weeks to reach the chapter; thus, a student has to spend roughly 6 study hours per week.

From the standpoint of student's study load, the ratio of 1:2 for the lecture to the study time is very heavy if we extrapolate it to 5 courses per term. Excluding lab and tutorial schedule, a student has to spend about 15 lecture hours and 30 study hours per week. I thus started the course redesign project with one initial goal: To teach an applied probability and statistics course in a way so that students can learn the course material efficiently.

The PSE textbooks [1-3] have an unenviable task of explaining mathematical probability concepts and applying them to engineering problems. In contrast, the standard mathematical probability and statistics textbooks [4-6] can afford to focus on the concepts and can cover more materials with fewer pages. The mathematical textbooks, however, are written for upper-year or graduate students, so that interpolating between these two exteremes is required to allow the students to learn course materials efficiently.

\section{COURSE REDESIGN METHOD}

From my experience working as a manager in a small oil and gas service company with a manufacturing shop, I found probability and statistics concepts useful for explaining sales data, assessing financial and safety risks, quantifying manufacturing data, predicting component failures, and negotiating prices with suppliers. This experience serves as a reminder for the problem solving and analysis skills students have to cultivate from the course. For instance, students should be able to select on their own the most appropriate probability distribution functions based on the data given for different problems posed in quizzes and exams. To cultivate these skills, students have to understand well the concepts and to train solving exercise problems.

My main goal of teaching the course therefore becomes twofold: (i) students learn the course material efficiently and (ii) students understand the concepts and develop problem solving skills by applying the concepts widely and flexibly.

I performed a comparison study of the six textbooks [1-6]. The standard PSE textbooks [1$3]$ were not economical nor clear in explaining concepts. Statistical independence and mutual exclusivity are not explained early in the probability chapter [1], or both concepts are not exploited in order to clarify presentations of the related concepts: probability distribution, conditional probability, combinatorics [2-3]. The standard PSE textbooks present the concepts not as a good story, but rather as a manual to be memorized. The manual approach was also adopted when discussing discrete and continuous distribution functions, by emphasizing their separate applications but not their connections to each other. The need to understand how these distribution functions are related to each other is crucial for students to correctly select the most appropriate function for a given problem. The intricate structures of the standard PSE textbooks, with many equation boxes, figures, and examples, seem to make the learning process for most students inefficient.

The standard mathematical probability and statistics (PS) textbooks [4-6], in contrast, describe the concepts much more clearly and efficiently. These textbooks give a clear and often thorough sequential explanation of the concepts. It is what I imagine the PSE course instructors prefer to read while assigning the standard PSE textbooks to their students. The mathematical rigor of these PS textbooks, however, prevents them from being used as PSE 
course textbooks. These PS textbooks do not offer many examples to solve as well.

Problem solving requires knowledge and creativity. A student with good knowledge of probability and statistics concepts will recognize relevant combinatoric features of a problem and impose constraints when needed to search for a solution. Solving such problem requires careful interpretations of sentences for clues. Although it's not realistic for the student to develop an expert knowledge on the course material within one term, the problem solving skills above are similar to what we expect from an expert [7].

When I first taught ENGG 319 in Fall 2012 with two other course instructors, we used the Montgomery and Runger textbook [1]. I made my own lecture slides for the two sections I taught to explain the equations listed in the textbook. The two instructors used chalk and blackboard. The average midterm exam marks for each four sections were equal at $67 \%$ and the average final exam marks for the four sections were between 49 and 51\%. Both midterm and final exam were open textbook and open notes. The other assessment methods were take-home assignments in which students could collaborate and hence were not compared.

While the textbook used has a wealth of exercise problems, it is taking too many pages to explain a concept. Its pedagogical approach is prescriptive and creates reading duplication for students who have to understand lecture slides that attempt to teach problem solving skills by mastering the concepts. The textbook used motivates the students to memorize the textbook formulas and as much as possible to perform pattern-matching with solved exercise and class problems when writing their midterm and final exam.

Through class discussions I had with the students from my sections, it was apparent that they wanted to understand the concepts well so that they could solve different problems. They often asked conceptual questions during class, such as the meaning of degrees of freedom in chi-square and Student's t distribution. One way to teach conceptual understanding and problem solving skills is to solve class examples as a bridge to discuss the concepts. The lecture materials are sequenced solved problems with increasing levels of difficulty. Based on my experience of teaching seven undergraduate courses, the example-driven teaching style is in fact ideal as most engineering students prefer class examples over mathematical derivations, especially for probability and statistics where students have to deal with uncertainties when solving problems even at its early stage of problem sentence interpretations [8].

I came to the conclusion that the reading duplication can only be removed when the textbook is synchronized with the lecture slides. The course redesign required a custom textbook that contains (i) derivations I have in the lecture slides when using the Montgomery and Runger textbook and (ii) explanations on concepts that are stitched together as a good story as exemplified by the PS textbooks [4-6]. The mathematical rigor had to be reduced, however, and presented more intuitively.

\section{CUSTOM TEXTBOOK}

The custom textbook is designed to be concise, has no example problems, and doesn't have many figures and tables. There are 10-25 problems at the end of each chapter. It is printed single-sided so that it can be stored with the corresponding lecture notes in a binder.

The writing process took 6 months (JanuaryJune 2013). The textbook has 6 chapters in 161 pages covering concepts of probability, such as statistical independence, mutual exclusivity, conditional probability; discrete probability distribution functions; continuous probability distribution functions; confidence intervals; hypothesis tests; and parameter estimators. The 
probability distribution functions start with binomial distribution and end with Weibull distribution in one continuous story. The confidence intervals are essentially a story about joint probability distribution functions, and normal, chi-square, and Student's t distribution; the hypothesis tests chapter further uses these distributions. The parameter estimators chapter explains the maximum likelihood function. The most difficult chapter to write is the first chapter which introduces the concepts without excessive formality. The first chapter is being revised to have a better story on mutual exclusivity, combinatorics, statistical independence, and conditional probability.

The other challenge is to create a sufficient number of exercise problems for students to work on. Each of 36 lectures has on average 2 class problems and the 6 chapters have a total of 72 exercise problems to be solved in weekly tutorials by teaching assistants. Students have a huge appetite in collecting solved problems and some of them communicated to me that these 144 problems were not sufficient. Exercise problems will be added to the revised edition to be released for the Fall 2014 term.

\section{COURSE DELIVERY}

On average each chapter needs 2 weeks of lectures so that the 6 chapters are completed in one term when used in Summer and Fall 2013 term. Each lecture focuses on solving two problems to illustrate a concept introduced. Each problem takes 10-15 minutes to solve. The remaining 20 minutes in a lecture is used to discuss theoretical aspects or derivations of a concept.

The online survey conducted in Summer 2013 term had a $78 \%$ participation rate (32 out of 41 students). Figure 1 shows an almost 2:1 margin on whether the textbook explains the concepts well.

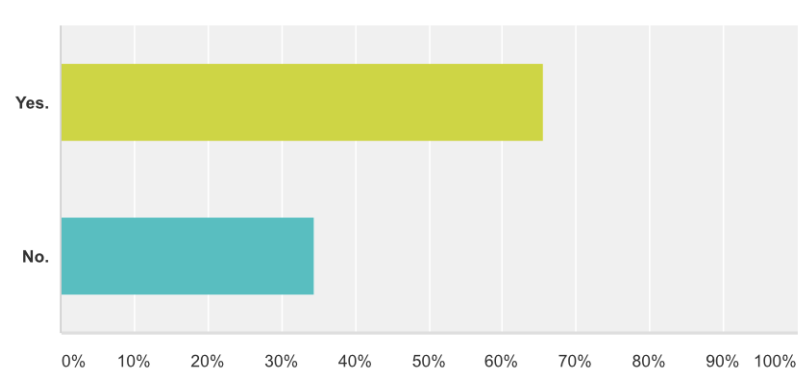

Figure 1. On whether the textbook explains the concepts well (Summer 2013 term).

Figure 2 shows an almost 8:1 ratio on whether the lectures apply the concepts well through class examples. It confirms my expectation that students prefer solved examples over concept derivation and overview to learn the course material.

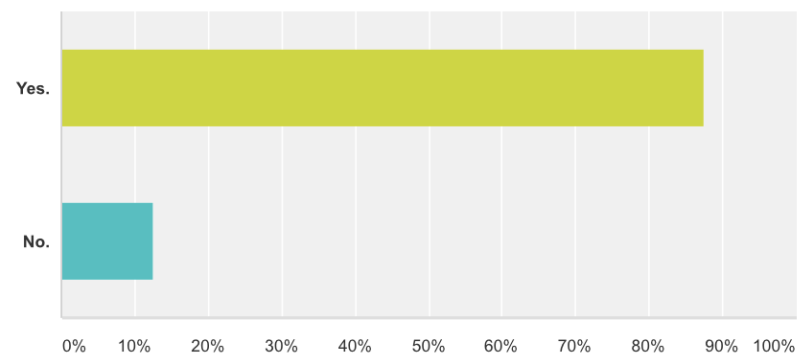

Figure 2. On whether the lectures apply the concepts well through (class) examples (Summer 2013).

Figure 3 shows a 2:1 margin on whether the students find the textbook and the problemfocused lectures work well.

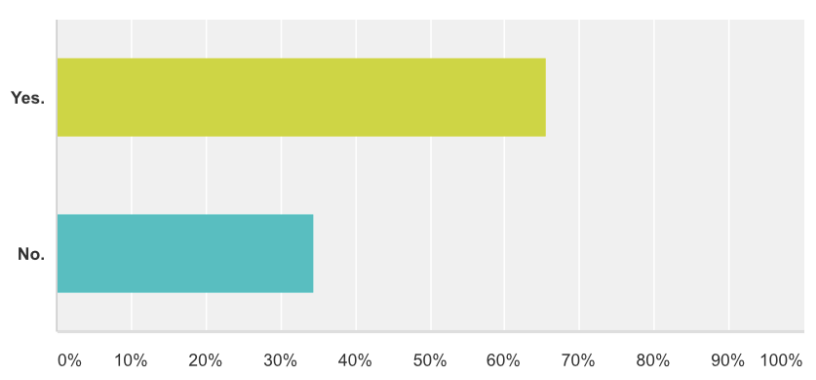

Figure 3. On whether the textbook and the lectures work together well (Summer 2013).

Figure 4 shows an almost 1:2 margin on whether the textbook explains the concepts well in Fall 2013 term, almost opposite result to 
Figure 1. There were no changes made to the textbook nor the lecture notes. All Fall sections used the same textbook and lecture notes. Figure 5 shows that the 8:1 margin in Summer 2013 was maintained in Fall 2013 on whether the lectures apply the concepts well through class examples.

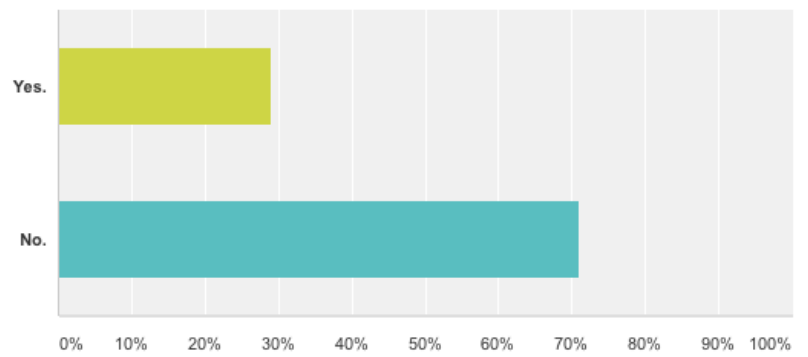

Figure 4. On whether the textbook explains the concepts well (Fall 2013 term).

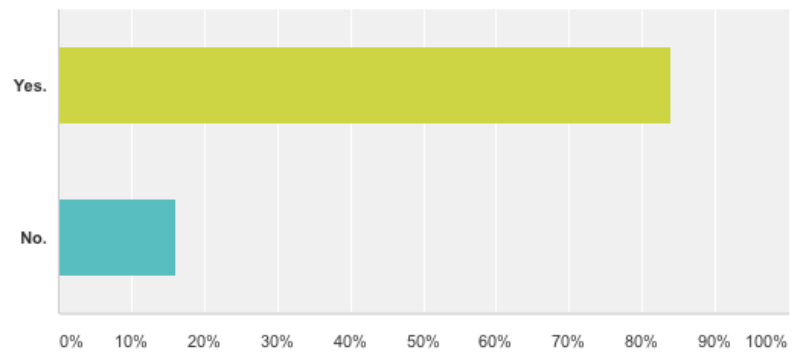

Figure 5. On whether the lectures apply the concepts well through (class) examples (Fall 2013).

Figure 6 shows an almost 1:1 ratio on whether the students find the textbook and the problemfocused lectures work well.

Even though students in both terms regard the lectures can explain the concepts well, the satisfaction level of the textbook decreases significantly in Fall 2013. From the survey comments students gave in Fall 2013, I found students wanted many more exercise problems and even less derivations during class. These concerns were voiced as well in Summer 2013. What was different in Fall 2013 from Summer 2013 is the class size. The Summer class had 41 students, while the Fall class had 135 students.

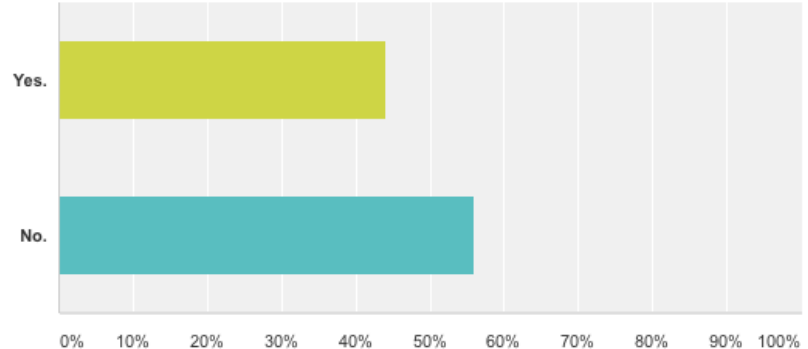

Figure 6. On whether the textbook and the lectures work together well (Fall 2013).

One reason why I believe the class size plays a dominant role in changing the student's attitude toward the textbook is that students actually regard the course to be useful for their future career as shown in Figure 7. Students paid attention to the course material in both terms. However, I was able to interact with students much better in the Summer term due to the much smaller class size. The frustration due to not many exercise problems was balanced by more class interactions in the Summer term.

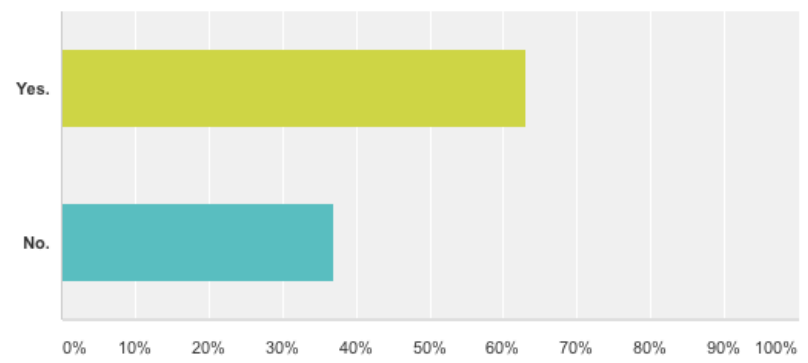

Figure 7. On whether ENGG 319 course will be useful for engineering career (Fall 2013).

The Summer term's average midterm and final exam marks were respectively $80 \%$ and $53 \%$, while the Fall marks were $77 \%$ and $52 \%$. There is a $10 \%$ midterm mark improvement between Fall 2012 and Fall 2013. The most difficult Fall 2012 midterm question was

"A joint density function is given as $f(x, y)=$ $6(1-y)$ for $0<x<y<1$. Find $E[x]$,"

while the most difficult Fall 2013 midterm question was

"The two chemical engineers are evaluating the probability of localized corrosion which will 
create a small hole of several millimeters in diameter and will cause an oil leakage. Given that there is a $4 \%$ probability of one-corrosion induced hole formation per $5 \mathrm{~km}$ due to metallurgical and electrochemical factors, how long should the pipeline be before there is a $99 \%$ probability that there is one hole?"

The most difficult Fall 2012 final exam question was

"A learning experiment requires a rat to run a maze (a network of pathways) until it locates one of 3 possible exits. Let $Y_{i}$ denote the number of times exit $i$ is chosen in successive runnings. Assume that the rat chooses an exit at random on each run. For general $n$, find $\operatorname{Cov}\left(Y_{2}, Y_{3}\right), "$ while the most difficult Fall 2013 final exam question was

"Electrical components have failure statistics that obeys Weibull distribution. Tests indicate that $5 \%$ of the electrical components fail within the first 2 years of continuous use and that $5 \%$ are still functioning after 10 years of continuous use. Assuming that inspected components were installed at the same time, determine the probability that during an inspection at 5 years of continuous use there are at most 4 components that must be tested before one failed component is found."

The exam questions become more applicationoriented after the custom textbook was adopted. Fall 2013 students had to also determine on their own the most appropriate probability distribution function.

\section{FUTURE WORK AND CONCLUSIONS}

In the next edition to be released for Fall 2014, the textbook will have a revised probability concepts chapter and more exercise problems. At least 20 exercise problems per chapter seems a good target to motivate students to develop problem solving skills. I plan to include engineering economic topics that require probability and statistics. Lastly, I plan to incorporate group projects where students work together to perform probability or statistics experiments. The engineering economic chapter and the group project addition are in the design stage.

In conclusion, the custom textbook is required to make students learn more efficiently and develop problem solving skills. Focusing lectures on solving problems helps students learn both the concepts and the skills.

\section{Acknowledgements}

The author thanks Dr. Bob Brennan and Dr. Ron Hugo for discussions during the textbook writing and the preparation of this paper.

\section{References}

[1] D. C. Montgomery and G. C. Runger, Applied Statistics and Probability for Engineers. Hoboken, NJ: John Wiley \& Sons, 2011 (5th Ed.), 765 pp. \{ISBN 978-0-470-05304-1\}

[2] R. E. Walpole, R. H. Myers, S. L. Myers, and K. Ye, Probability \& Statistics for Engineers \& Scientists. Boston, MA: Prentice Hall, 2012 (9th Ed.), 791 pp. \{ISBN 978-0-321-62911$1\}$

[3] R. A. Johnson, Miller and Freund's Probability and Statistics for Engineers. Boston, MA: Prentice Hall, 2011 (8th Ed.), 544 pp. \{ISBN 978-0-321-64077-2\}

[4] W. Feller, An Introduction to Probability Theory and Its Applications, Volume 1. John Wiley \& Sons (3rd Ed.), 497 pp. \{ISBN 978-0-471-25708-0\}

[5] W. Feller, An Introduction to Probability Theory and Its Applications, Volume 2. John Wiley \& Sons (2nd Ed.), 667 pp. \{ISBN 0-471-25709-5\}

[6] R. V. Hogg and A. T. Craig, Introduction to Mathematical Statistics. Upper Saddle River, NJ: Prentice Hall (5th Ed.), 564 pp. \{ISBN 0-02-355722-2\}

[7] J. Wiley, "Expertise as mental set: The effects of domain knowledge in creative problem solving," Memory \& Cognition, vol. 26, no. 4, pp. 716-730 (1998).

[8] F. M. A. Acosta, "Hints for the improvement of quality teaching in introductory engineering statistics courses," Journal of Engineering Education, vol. 25, no. 4, pp. 263-280 (2000). 